\title{
New Organic Compounds Detection and Potential Removal in Crude Phosphoric Acid using Waste Sludge
}

\section{Saber Ahmed Ibrahim}

National Research Centre

Ahmed Masoud

NMA: Nuclear Materials Authority

Mohamed Helmy Taha

Nuclear Materials Authority

Amr Sayed Meawad ( $\sim$ ameawad@science.helwan.edu.eg)

Helwan University Faculty of Science https://orcid.org/0000-0003-0061-6027

\section{Research Article}

Keywords: Waste sludge, Crude phosphoric acid, Organic species, Sorption

Posted Date: February 8th, 2021

DOI: https://doi.org/10.21203/rs.3.rs-157157/v1

License: (c) (i) This work is licensed under a Creative Commons Attribution 4.0 International License. Read Full License 
$4 \quad{ }^{1}$ Packaging Materials Department, National Research Centre, Elbehoth Street 33, 12622, Dokki, Cairo, Egypt. 


\section{Abstract}

26 Some organic compounds in phosphoric acid are a potential mediator of adverse environmental impacts

27 on soil. This work aims to detect and reduce the content of organic compounds in crude phosphoric acid

28 using waste sludge, from water treatment plants, as a low-cost sorbent. Gas chromatography/Mass

29 spectrometry (GC/MS) was used to detect the organic species in crude phosphoric acid, while X-ray

30 fluorescence (XRF), X-ray Diffraction (XRD), and Attenuated total reflectance Fourier transform

31 infrared (ATR-FTIR) spectroscopy were used to characterize waste sludges. Practically, three sludge

32 samples were utilized and different factors including shaking time, sorbent dose, and phosphoric acid

33 concentration were studied.

34 The results of GC/MS revealed that crude phosphoric acid contains bis [tert-butyl(dimethyl)silyl]

35 azelaate, dibutyl phthalate, and 2,6-di-tert-butyl-4-methylphenol as the main organic species. Moreover,

36 the clay content and the surface charge of sludge strongly affect the removal efficiency of organic

37 species. Kinetic analysis using Lagregran pseudo-first-order, pseudo-second-order, Morris-Weber, and

38 Elvoich models display that the sorption process using waste sludges is a chemisorption process. Finally,

39 the three sludge samples exhibit potential sorbents for the clarification of phosphoric acid and

40 sequentially to produce green phosphate fertilizers.

42 Keywords:

43 Waste sludge; Crude phosphoric acid; Organic species; Sorption 


\section{1. Introduction}

46 Phosphorus (P) is one of the vital macronutrients required for plant growth as well as human life.

47 Phosphorus was utilized for increasing crop products since the 1950s (Stewart and Roberts 2012). The

48 United Nations reported that the world population is expected to become about 9 billion by 2050, and

49 the food demand will increases by $60 \%$ for the same period that sepsequently will rise the global

50 phosphors demand (FAO 2018). Phosphorus security is considered one of the greatest global

51 sustainability challenges in the twenty-first century (Cordell and White 2014). Phosphorus management

52 is very important for sustainable food and agriculture, particularly in food-deficient and phosphorus-

53 scarce countries (Cordell et al. 2015).

54 Phosphate rock is a nonrenewable natural resource that is used to describe phosphate-bearing minerals.

55 Approximately $90 \%$ of the phosphate rock production worldwide is utilized in the fertilizer industry, and

56 the other $10 \%$ is used in the animal feeds, detergents, and chemicals industries (Hellal et al. 2019;

57 Nedelciu et al. 2020). Phosphate rock sources may be sedimentary origin as in Florida, Jordan, North

58 Africa, and igneous origin as in South Africa, Brazil, Russia, or secondarily metamorphic origin as in

59 India. Phosphate rocks exhibit different chemical, physical, and crystallographic characteristics based

60 on its geological history and origin (Fayiga and Nwoke 2016).

61 It is well known that phosphate rocks contain organic compounds as a result of the biological

62 sedimentation of sea organisms (Taha et al. 2019). In addition to organic compounds, phosphate rock is

63 contains different hazardous elements such as U, Cd, and As (Fayiga and Nwoke 2016). Organic

64 compounds as well as other harmful elements are introduced to phosphoric acid and phosphate fertilizers

65 during the acidulation of phosphate rock (Zhang and Zhang 2010; Fayiga and Nwoke 2016). Most of

66 previous studies reported that the organic compounds in the phosphoric acid mainly consists of humic

67 compounds, aromatics, and other saturated and unsaturated fatty acids (Awwad et al. 2013; Hamza et al. 
2013; Fawzy et al. 2018; El Naggar et al. 2019), however, , the main organic compounds in wet crude

69 phosphoric acid have not been detected.

70 Organic compounds present in phosphoric acid have a negative impact on the quality and the quantity

71 of the produced phosphoric acid whereas they give a dark color to the produced acid and affect the

72 crystallization of the phosphogypsum (Singh et al. 2016; Taha et al. 2019). Furthermore, organic

73 compounds result in serious operating problems during the application of liquid-liquid method for the

74 recovery of uranium from phosphoric acid as well as the purification of phosphoric acid, whereas organic

75 compounds accumulates and coagulates heavly at the interfacial area between the phosphoric acid and

76 organic solvent which leads to the losses of the organic solvent and negatively impact on the process

77 economy (Dissanayake and Chandrajith 2009; Awwad et al. 2013; Singh et al. 2016; El Naggar et al.

78 2019). Also, organic compounds forms stable toxic complexes with the harmful elements in the

79 phosphoric acid, which accumulate in the environment as a result of the continuous application of

80 phosphate fertilizers and also transfer to the human body through the food chain (Fayiga and Nwoke

81 2016; Taha et al. 2019).

82 Accordingly, the reduection of the organic compound from phosphoric acid is an important process in

83 respect to improve the quality of phosphoric acid and produce eco-friendly fertilizers. Various methods

84 were applied for the reduction of organic compounds from crude phosphoric acid for example liquid-

85 liquid extraction or sorption (Awwad et al. 2013; Hamza et al. 2013; Singh et al. 2016; Fawzy et al.

86 2018; El Naggar et al. 2019). Several materials were investigated for achieving this proposes such as

87 clays (Hamza et al. 2015; Singh et al. 2016) and activated bio-chars (El Naggar et al. 2019; Taha et al. 88 2019).

89 Sludge is the waste materials generated from water treatment plant. The production of sludge is expected

90 to be increased shortly as a result of urbanization and industrial development (Rashed 2018). The

91 chemical and physical properties of the sludge are varied as a result of the difference in the water 
92 treatment technology, hydrogeology, and geology of the intake area, as well as the chemical composition

93 of the utilized raw materials (Evuti and Lawal; Wołowiec and Bajda 2017). The management of sludge

94 could be performed using several methods such as landfilling (Grassi et al. 2012), road surfacing

95 (Jamshidi et al. 2012), and incineration (Yu and Zhong 2006).

96 Proper management of sludge in an eco-friendly and economical manner is very interesting. Sludge has

97 good sorption properties (Yu and Zhong 2006). Recently, sludge has been utilized for the elimination of

98 heavy metals from wastewater (Ragheb 2018; Rashed 2018; Wołowiec et al. 2019; Bogusz et al. 2019).

99 However, sludge has never been applied for the purification of industrial phosphoric acid. In this regard,

100 the present work aims to detect the main organic compounds in crude phosphoric acid as well as the

101 application of waste sludge as an efficient sorbent for the retention of organic species through batch

102 investigation in order produce eco-friendly phosphate fertilizers and reduce the accumulation of sludge

103 in the environment.

104 2. Experimental procedures

\section{2.1. Materials}

106 Sludge samples designated here as S1, S2, and S3, were collected from three different water treatment 107 stations namely El-Marg, Al-Obour, and El-Sheikh Zayed, respectively. The samples were washed with 108 double distilled water, left overnight in an oven at $110^{\circ} \mathrm{C}$ for complete drying, and finally left for cooling 109 in a desiccator for further analysis.

110 Commercial crude phosphoric acid, containing $\left(\mathrm{P}_{2} \mathrm{O}_{5}=26.5 \%, \mathrm{CaO}=0.34 \%, \mathrm{Fe}_{2} \mathrm{O}_{3}=1.1 \%, \mathrm{~F}=0.64 \%\right.$,

$111 \mathrm{U}(\mathrm{VI})=40 \mathrm{ppm}$ and organic compounds $=450 \mathrm{ppm})$ was purchased from Abu Zaabal Company for

112 Fertilizer and Chemical Materials. Shimazu UV-visible 160 A spectrophotometer was used to determine

113 the content of organic compounds, iron and uranium.

\section{2.2. Characterization methods}


115 X-ray Fluorescence (XRF) spectroscopy (Axios, sequential WD-XRF spectrometer, PANalytical) was

116 used to determine the chemical composition of sludge samples. The phase composition of sludge samples

117 was determined using X-ray diffraction (XRD, Bruker D8 advance X-ray diffractometer). The patterns

118 were recorded by $\mathrm{Cu}-\mathrm{K} \alpha$ radiation with $\lambda$ of $1.5406 \AA$ and $40 \mathrm{kV}$ tube voltage, $40 \mathrm{~mA}$ tube current, $2 \theta$ scan

119 range of $4-90^{\circ}, 0.01^{\circ}$ step width, and scan speed $0.5^{\circ} / \mathrm{min}$. X'Pert High Score ${ }^{\mathrm{TM}}$ (version 2.0.1) was used

120 to perform a semi-quantitative analysis of the crystalline phases in the sludge samples (Degen et al. 2014).

121 Attenuated total reflectance Fourier transform infrared (ATR-FTIR) spectroscopy (Spectrum Two IR

122 Spectrometer - PerkinElmer, Inc., Shelton, USA) was used to identify the main functional groups of sludge

123 samples. acquisition conditions were 64 scans and $4 \mathrm{~cm}^{-1}$ resolution in wavenumbers ranging from 4000

124 to $400 \mathrm{~cm}^{-1}$.

125 The mean diameter of the sludge particles was determined at $170^{\circ}$, by dynamic light scattering (DLS)

126 (NICOMP 380 ZLS, PSS, Santa Barbara, CA, USA). Also, the zeta potentials of the three samples were

127 measured at $18^{\circ}$. Nitrogen adsorption-desorption measurements were carried out at $77.35 \mathrm{~K}$ on a Nova

128 Touch LX ${ }^{4}$ Quantachrome, USA to determine the Brunauer-Emmett-Teller (BET) surface area. Before

129 measurement, samples were kept in a desiccator until testing. Samples were cooled with liquid nitrogen

130 and analyzed by measuring the volume of gas $\left(\mathrm{N}_{2}\right)$ adsorbed at specific pressures. The pore volume was

131 taken from the adsorption branch of the isotherm at $\mathrm{P} / \mathrm{Po}=0.995$ assuming complete pore saturation.

132 Gas chromatography/mass spectrometry (GC/MS) HP5890 Series II Gas Chromatograph, HP 5972 Mass

133 Selective Detector and Agilent 6890 Series Autosampler (Agilent Technologies, USA) was used to

134 identify the chemical constituents of crud phosphoric acid solution. A Supelco MDN-5S $30 \mathrm{~m} \times 0.25 \mathrm{~mm}$

135 capillary column with a $0.5 \mu \mathrm{m}$ film thickness was used with helium as the carrier gas at a flow rate of 1.0

$136 \mathrm{~mL} / \mathrm{min}$. The $\mathrm{GC}$ oven temperature was programmed at an initial temperature of $40{ }^{\circ} \mathrm{C}$ for 5 minutes, then

137 heated up to $140{ }^{\circ} \mathrm{C}$ at $5^{\circ} \mathrm{C} / \mathrm{min}$ and held at $140{ }^{\circ} \mathrm{C}$ for $5 \mathrm{~min}$, then heated to $280{ }^{\circ} \mathrm{C}$ at $9{ }^{\circ} \mathrm{C} / \mathrm{min}$ and held

138 for five additional minutes. Injector and detector temperatures were set at $250{ }^{\circ} \mathrm{C}$. Mass spectrometry was 
139 run in the electron impact mode $(\mathrm{EI})$ at $70 \mathrm{eV}$. The identification of the chemical constituents was

140 determined by their GC retention times, retention indices, and interpretation of their mass spectra and

141 confirmed by mass spectral library search using the National Institute of Standards and Technology

142 (NIST) database with those of authentic samples or published data (Shahat et al. 2011). The retention

143 indices were calculated for all of the volatile constituents using a homologous series of C8-C20 n-alkanes.

144 2.3. Sorption methodology

145 The three sludge samples were investigated for the sorption of organic species from crude phosphoric

146 acid $(4.5 \mathrm{M})$ in batch teqniche. All tests were achieved in polyethylene type using a thermostatic shaking

147 water bath. The influence of reaction time, sludge amount of addition, phosphoric acid concentration on

148 the removal percent have been examined. In details, $40 \mathrm{~mL}$ of liquid phase has been shaken with $0.4 \mathrm{~g}$

149 of the sorbent at $298 \pm 1 \mathrm{~K}$ for $24 \mathrm{hrs}$. The mean values $\leq 4 \%$ relative errors were accepted for the

150 performed experiments. After equilibration, the sludge was removed from the phosphoric acid. The

151 concentration of organic compounds in crude acid has been measured using a spectrophotometer at 418

$152 \mathrm{~nm}$ (Taha et al. 2019).

153 The following equations have been applied to figure out the impact of the main variables on the removal

154 efficiency of organic compounds from industrial phosphoric acid:

$$
\begin{aligned}
E \% & =\frac{1-C_{e}}{C_{o}} X 100 \% \ldots \ldots(1) \\
q_{e} & =C_{o}-C_{e} X \frac{V}{m} \ldots \ldots(2)
\end{aligned}
$$

157 where $\mathrm{Co}$ and $\mathrm{Ce}$ are the $\mathrm{OM}$ concentration $\left(\mathrm{mg} \mathrm{L}^{-1}\right)$ before the adsorption and at equilibrium,

158 respectively, qe $\left(\mathrm{mg} \mathrm{g}^{-1}\right)$ is the amount of OM sorbet, $\mathrm{V}$ is the volume of phosphoric acid (L), and $\mathrm{m}$ is

159 the mass of the sludge $(\mathrm{g})$.

160 3. Results and Discussions

$161 \quad$ 3.1. Characterization of sludge samples 


\subsubsection{Physical characterization}

163 Particle size distributions of different sludge samples were investigated to examine the mean particle

164 size and polydispersity index of Gaussian distribution. The samples S1, S2 and S3 were measured and

165 the bell shape distribution forms were clearly detectable in Fig. 1a. The mean particle sizes for S1, S2

166 and S3 are 1725, 748 and $755 \mathrm{~nm}$, respectively. In addition, the poly dispersity index was laid between

1670.2 and 0.5 that indicated to unimodal particle size with narrow distributions (Ibrahim and Voit 2009).

168 Selected sludges were directly measured without further treatment like grinding or burning. Big clusters

169 of sludge with accumulated inorganic and organic substance resulted from Nile River were presence in

170 range 0.7 to $1.7 \mu \mathrm{m}$. neither big particles of sludge nor excellent polydispersity indices were pointed to

171 homogenized particle size (Ahmed et al. 2019; Meawad and Ibrahim 2019).

172 Zeta potential has a great affect in the stability of dispersed solution from sludge in aqueous medium.

173 The average zeta potentials of sludge over 11 measurements for each sample were illustrated in Fig. 1 b.

174 Investigated sludge samples S1, S2 and S3 by DLS measurements with mean zeta potential $-5.55,-27.93$

175 and $-34.14 \mathrm{mV}$, respectively. In addition, the average mobilities of dispersed particles were $-0.39,-2.02$

176 and -2.38 M.U. for S1, S2 and S3, respectively. Previous results indicated to the stability of samples S2

177 and S3 are higher than S1 with low mobility and low zeta potential. The separation of organic

178 compounds was depending on the fast precipitation of sludge during physical adsorption mechanism.

179 The surface area is one of unique phenomena related to the particle size with inverse proportions

180 (Ibrahim et al. 2018). Surface area measurement with related indices for sludge samples were tabulated

181 in Table 1. The isotherm branch of nitrogen gas on dry degassed sludge power with adsorption trend

182 were applied to calculate BET values 19,94 and $102 \mathrm{~m}^{2} / \mathrm{g}$ for sludge sample S1, S2 and S3, respectively.

183 The adsorption indices were indicated to perfect trend of measured points with correlation coefficient

$184 \approx 1$ as first order equation of linear relationship. The particle size results have a great agreement with

185 confirmation to each other's through increasing the surface area with decreasing of particle size from 
186 S3, S2 to S1. Overall, the physical characterization measurements are verified the stability, size and

187 surface area for sludge samples as mentioned theoretically and previous research (Ibrahim et al. 2016;

188 Meawad and Ibrahim 2019; Abdelraof et al. 2020).

189 3.1.2. Chemical characterization

190 The chemical composition of sludge samples is presented in Table 2. The XRF analysis shows that silica

191 and alumina are the main oxides of the three sludges due to the precipitated clay. Fig. 2 shows the FTIR

192 spectra of the three sludge samples. In all spectra, the bands at $3400 \mathrm{~cm}^{-1}$ and $1630 \mathrm{~cm}^{-1}$ are related to

193 the stretching and bending vibrations of -OH group of the interlayer water molecule, respectively. The

194 band located at $1070 \mathrm{~cm}^{-1}$ assigned to $\mathrm{T}-\mathrm{O}-\mathrm{Si}(\mathrm{T}=\mathrm{Si}$ or $\mathrm{Al})$ asymmetric stretching. Other significant

195 bands are related to symmetric stretching of $\mathrm{Si}-\mathrm{O}-\mathrm{Si}$ and bending of $\mathrm{Si}-\mathrm{O}$ are located at around $800 \mathrm{~cm}^{-}$

$196{ }^{1}$ and $455 \mathrm{~cm}^{-1}$, respectively. The presence of such bands confirms the mineralogical analysis about the

197 presence of aluminosilicate phases in sludge samples. Furthermore, the peak around $1400 \mathrm{~cm}^{-1}$ is likely

198 attributed to carbonate species, while the peaks at $2900 \mathrm{~cm}^{-1}$ and $2985 \mathrm{~cm}^{-1}$ correspond to stretches of

199 C-H carbons of organic species in S2 sludge. The results of XRD, Fig. 3, indicated the presence of

200 feldspar-type minerals, quartz, clay minerals (illite, kaolinite and chlorite), carbonate minerals (calcite,

201 aragonite and dolomite) as main crystalline phases as well as mica, anhydrite, apatite and other minerals

202 as minor phases. The related semi-quantitative data are presented in Table 3. It is well known that the

203 clay minerals content and the charge on clay surface play an important role in the efficient sorption of

204 organic compounds (Lützow et al. 2006; Setia et al. 2014). As shown, the total clay content in S1 is

205 higher than that in S2 and S3, while the feldspar content is much lower. Moreover, the quartz content in

206 S1 and S2 are much higher than that in S2.

207 3.2. Detection of organic constituent in crude phosphoric acid

208 The accumulation of organic compound as well as potentially toxic elements in the environment has

209 becomes a global concern. Continuous application of phosphate fertilizers will increase the accumulation 
210 of the organic compounds and other hazardous to the ecosystems. Therefore, the detection of the main

211 organic compounds in crude phosphoric acid is important for a successive process for the removal of 212 these contaminants.

213 The obtained results in Fig.4 clear that the main organic compounds in crude phosphoric acid is mainly 214 composed of three components: azelaic acid (diTBDMS: (Bis [tert-butyl(dimethyl)silyl] azelaate),

215 Butylated hydroxytoluene (2,6-Di-tert-butyl-4-methylphenol), and Dibutyl phthalate.

216 Azelaic acid, diTBDMS is a saturated dicarboxylic acid that belongs to the class of organic compounds

217 known as medium-chain fatty acids. It has the following formula and molecular weight: $\mathrm{C} 21 \mathrm{H} 44 \mathrm{O} 4 \mathrm{Si} 2$

218 and $416.74 \mathrm{~g} / \mathrm{mol}$ (Wheeler et al. 2000). 2, 6-Di-tert-butyl-4-methylphenol (Butylated hydroxytoluene)

219 is a lipophilic organic compound with a chemical formula of $\mathrm{C}_{15} \mathrm{H}_{24} \mathrm{O}$ and a molecular mass of 220.35

$220 \mathrm{~g} / \mathrm{mol}$ (US National Library of Medicine 2020). Butylated hydroxytoluene (BHT) is a member of the

221 alkyl phenols broad group which has been widely used as an antioxidant food additive. BHT is rapidly

222 decomposed forming different metabolites in the environment such as in water and soils (Ryssel et al.

223 2015). BHT is hardly biodegradable and therefore the bioaccumulation of BHT and its derivatives

224 exhibit high toxicity to aquatic organisms, and they are considered as a human health risk from a food

225 safety point of view. The BHT and its metabolites are on the undesirable substances list "Danish

226 Environmental Protection Agency" (Norwegian Scientific Committee for Food Safety 2009; Ryssel et

227 al. 2015).

228 Dibutyl phthalate (DBP) it is a phthalate ester with the following formula and molecular mass: $\mathrm{C}_{16} \mathrm{H}_{22} \mathrm{O}_{4}$ 229 and $278.34 \mathrm{~g} / \mathrm{mol}$ (2020). Dibutyl phthalate is a ubiquitous environmental contaminant that is used 230 widely as plasticizer in modern agricultural production due to wastewater irrigation, and the common 231 applications of agricultural chemicals (He et al. 2015). The U.S. Environmental Protection Agency 232 classified the Dibutyl phthalate as an endocrine disruptor chemical and an environmental pollutant, 
233 which means that the distribution of DBP through the soli poses threatens to both the environment as

234 well as the human food chain (Bui et al. 2016).

\section{$235 \quad$ 3.3. Sorption investigation}

236 The following section discusses the application of three sludge wastes for the clarification of crude phosphoric acid in order to obtain a proper acid for clean fertilizers. The impact of shaking time, phosphoric acid concentration, and sludge amount of addition, as main variables, on the organic compounds adsorption percent have been tested. The sorption isotherms, as well as kinetics, have been performed in order to provide useful data required for the scale-up experiments and the process design.

\subsubsection{Effect of shaking time}

242 Several experiments were achieved to investigate the impact of reaction time in the range of 1-120 min

243 on organic species sorption from commercial phosphoric acid (4.5 M) using different sludge wastes. In

244 detail, the three waste sludge has been shaken with crude phosphoric acid with sorbent dose of $10.0 \mathrm{~g} /$

245 L, shaking speed of $150 \mathrm{rpm}$, and room temperature.

246 The variation of organic compounds adsorption percent as a function of shaking time has been illustrated

247 in Fig.5. From the data, it is evident that the sorption of organic species from industrial phosphoric acid

248 by the three sludge is a fast reaction whereas the reaction equilibrium is obtained after 30 min for the

249 three sorbents. In addition, the three sorbent exhibit the same sorption performance whereas the sorption

250 reaction consists of two stages; the first stage starts from 1 to $30 \mathrm{~min}$ and is characterized by a high

251 adsorption rate of reaction. Numerically, organic compounds sorption efficiency increased from 19.0 to

25254.0 for $\mathrm{S} 1$, from 13.1 to 48.0 for $\mathrm{S} 2$, and 17.8 to $48.4 \%$ for $\mathrm{S} 3$, as the shaking time increased from 1 to

25330 min respectively. This behavior may be due to the presence of free active sites on the surface of the 254 waste sludge (Zhang et al. 2015; Taha et al. 2018). The second stage shows a slow rate of reaction 255 whereas the organic compounds sorption percent is slightly varied from about 54.0 to $58.5 \%$ for S1, 256 from 48.0 to $51.7 \%$ for $\mathrm{S} 2$, and from 48.4 to $50.7 \%$ for S3 as the shaking time increase from 30 to 120 
min. This performance may be due to that most of the sorbent surface active sites were occupied,

258 therefore organic compounds molecules need more time for the diffusion and reaction with the inside

259 active groups (Zhang et al. 2015; Taha et al. 2018). This was consistent with other previous reports

260 (Nawar et al. 2015; Ait Ahsaine et al. 2017; Ali et al. 2019; Taha et al. 2019). To ensure that complete

261 equilibrium was attained, other subsequent experiments were performed at 120 min.

\section{3.3.2. Influence of phosphoric acid concentration}

263 To investigate the impact of phosphoric acid concentrations ranging from 4.5 to $8.0 \mathrm{M}$ on the sorption

264 of organic compounds using different waste sludge sorbents, a set of experiments were achieved at 120

265 min reaction time, $100 \mathrm{rpm}$ stirring speed, and $25 \pm 1^{\circ} \mathrm{C}$. The collected data has been illustrated in Fig.

$266 \mathbf{6}$ as a relation between organic compounds sorption \% and phosphoric acid molarity. The exhibited data

267 declare that the increase in phosphoric acid concentration has the same impact on the sorption behavior

268 of the three investigated waste sludge sorbents. In details, organic compounds sorption efficiency has

269 drastically reduced from 59.0 to $30.2 \%$ for S1, from 52.3 to $26.0 \%$ for $\mathrm{S} 2$, and from 50.7 to $22.9 \%$ for

270 S3 sorbent as the phosphoric acid concentration increased from 4.5 to $8.0 \mathrm{M}$. This behavior could be

271 attributed to that as the phosphoric acid molarity increases, the number of phosphoric acid molecules

272 increases which, in turn, increase the coverage of the surface active sites of the sorbent particles by the

273 excess acid molecules and in turn decrease the sorption capability of the sorbent. Also, the increase of

274 acid molarity results in the increase of the acid bulk density which effects negatively on the diffusion of

275 the organic compounds molecules to the sorbent surface (Morsy and Hussein 2012; Taha et al. 2019).

276 3.3.3. Effect of sorbent dose

277 Fig.7 explores the impact of S1, S2, and S3 waste sludge amount of addition on the reduction of organic

278 compounds from industrial phosphoric acid. In details, the sorbent amount of addition covers the range

279 from 0.5 to $20 \mathrm{~g} / \mathrm{L}$ however, the other controlling conditions were kept at a phosphoric acid concentration

280 of 4.5 M, room temperature, $100 \mathrm{rpm}$ stirring speed, and $120 \mathrm{~min}$ shaking time, to optimize the required 
sorbet dose for maximum organic compounds removal. It is obvious that the organic compounds

282 adsorption percent increases by increasing the three waste sludge sorbents' amount of addition. This performance may be attributed to the existence of more active reaction sites as the sorbent dose increases (Zou et al. 2017; El Naggar et al. 2019). Numerically, The organic compounds sorption changed from 16.2 to $71.5 \%$ for $\mathrm{S} 1$, from 11.0 to $61.7 \%$ for $\mathrm{S} 2$, and from 13.5 to $59.1 \%$ for $\mathrm{S} 3$ sorbent as the waste sludge dose increased from 0.5 to $20.0 \mathrm{~g} \mathrm{~L}^{-1}$. It is worth noted that, the sorption capacity of the investigated three waste sludge sorbents negatively impacted by the increase in the sorbent amount of addition. Specifically, the sorption capacity, qe value, decreased from 145.6 to $16.1 \mathrm{mg} / \mathrm{g}$ for $\mathrm{S} 1$, from 99.0 to $13.9 \mathrm{mg} \mathrm{g}^{-1}$ for $\mathrm{S} 2$, and from 121.5 to $13.3 \mathrm{mg} \mathrm{g}^{-1}$ for $\mathrm{S} 3$ as the sorbent dose increased from 0.5 to $20.0 \mathrm{~g} \mathrm{~L}^{-1}$. This performance could be attributed to the sorbent active sits were not freely available for binding with organic compounds molecules, and the low concentration of organic compounds species could not meet the adsorption capacities of adsorbents, and thereby decreased the qe (Zou et al. 2017; El Naggar et al. 2019). This result is consistent with studies applying alum sludge and sewage sludge for wastewater treatment (Nawar et al. 2015; Abo-El-Enein et al. 2017).

\subsection{The uptake kinetics}

The uptake kinetics is important in the solid-liquid reactions for better understanding the rate of reaction and the possible adsorption mechanism. In this section, the kinetics of OM removal from industrial phosphoric acid using S1, S2, and S3 waste sludge were performed. Accordingly; the equations of the following kinetic models namely; pseudo-first-order, pseudo-second-order, Elvoich, and Weber and Morris kinetic models (Eq. (3), Eq. (4), Eq. (5) and Eq. (6) respectively) have been applied to the adsorption data as shown in Figs. 8-11, respectively (Kim and Kim 2019; Kang and Kim 2019). The values of the kinetic model constants have been calculated and displayed in Table 4. The coefficient of interaction. 


$$
\log \left(q_{e}-q_{t}\right)=\log q_{e}-\left(\frac{K_{1}}{2.303}\right) t \ldots \ldots
$$

$$
\frac{t}{q_{t}}=\frac{1}{K_{2} q_{e}^{2}}+\left(\frac{1}{q_{e}}\right) t \ldots \ldots \text { (4) }
$$

$$
\mathrm{q}_{\mathrm{t}}=\frac{1}{\beta} \ln (\alpha \beta)+\frac{1}{\beta} \ln \mathrm{t} \ldots \ldots(5)
$$

$$
q_{t}=K_{i d} \mathrm{t}^{0.5}+C
$$

Where $\boldsymbol{q}_{\boldsymbol{t}}$ is the sorption capacity at time $\mathrm{t}\left(\mathrm{mg} \mathrm{g}^{-1}\right) ; \boldsymbol{K}_{\mathbf{1}}$ is the rate constant of the pseudo first-order sorption $\left(\mathrm{min}^{-1}\right), \boldsymbol{t}$ is time (min); $\boldsymbol{K}_{2}$ is the rate constant of the pseudo second order kinetics ( $\left.\mathrm{g} / \mathrm{mg} \mathrm{min}\right)$;

$311 \boldsymbol{\beta}$ is referred to the surface coverage extension and the activated energy for chemisorption and $\boldsymbol{\alpha}(\mathrm{mg} / \mathrm{g}$.

$312 \mathrm{~min})$ is the initial adsorption rate; $\boldsymbol{K}_{\boldsymbol{i} \boldsymbol{d}}$ is intraparticle diffusion rate constant $\left(\mathrm{mg} / \mathrm{g} . \mathrm{min}^{1 / 2}\right) ; \boldsymbol{C}$ is the 313 initial adsorption $\left(\mathrm{mg} \mathrm{g}^{-1}\right)$.

314 The experimental data have been analyzed using the Pseudo-first order equation as explored in Fig. 8.

315 The Figure obvious that the relation between Log (qe-qt) vs time yield straight lines with poor correlation

316 coefficient which indicated that the organic compounds sorption process is not fitted well with the

317 Lagergren equation. In many cases in the literature, Lagergren kinetic model was commonly is not fitting 318 well for the whole reaction times, however it applicable only for describing initial stage of the sorption 319 processes (Ait Ahsaine et al. 2017). The Pseudo-second order reaction equation (McKay equation) was 320 examined to fit the obtained results as shown in Fig. 9. It is obvious that the relation between $t / q t$ as a 321 function of sorption time gives an excellent linear relationship with a correlation coefficient equal to 3220.99 for the investigated three waste sludge. Besides, the experimental sorption capacity qe exp for S1, 323 S2, and S3 sorbents is consistent with the calculated sorption capacity qe cal. This evidence that the 324 Pseudo-second order kinetic equation could be successfully describe the organic compounds sorption 325 from crude phosphoric acid using S1, S2, and S3 sludge. This means that the organic compounds sorption 326 process is chemisorption and there is electron transfer or electron sharing between the applied waste 
327 sludge sorbents and the organic compounds species (Taha et al. 2018, 2019). This results in consistent

328 with other previous reports (Hamza et al. 2013; Ait Ahsaine et al. 2017; Ali et al. 2019; Taha et al. 2019).

329 The half-equilibrium time, $\mathrm{t}_{1 / 2}(\mathrm{~h})$, and the initial adsorption rate, $\mathrm{h}(\mathrm{mol} / \mathrm{g} . \mathrm{h})$ for $\mathrm{S} 1, \mathrm{~S} 2$ and $\mathrm{S} 3$ waste

330 sludge sorbents were calculated from equations 1 and equation presented in (El Naggar et al. 2019). The

331 explored results in Table 4 reveal that S2 sludge has the highest half-equilibrium time (5.3) while S3 has

332 the lowest value (3.6). Nevertheless, S1 and S3 sorbents have the greatest initial adsorption rate (6.69

333 and $6.55 \mathrm{~mol} / \mathrm{g} . \mathrm{h})$ and S2 sorbent has the lowest value (4.6 mol/g.h). The sorption capacity at equilibrium

334 for the three applied sludge sorbents could rank as the following S1 > S2 > S3. It worth noted that the

$335 \mathrm{~S} 3$ sorbent has the highest surface area $\left(\mathrm{m}^{2} / \mathrm{g}\right)$ followed by $\mathrm{S} 2\left(\mathrm{~m}^{2} / \mathrm{g}\right)$ and then S1 sorbent $\left(\mathrm{m}^{2} / \mathrm{g}\right)$ even

336 though, S3 sorbent exhibits the lowest sorption capacity and S1 show the highest organic compounds

337 sorption capacity. This means that the synergistic effect of the sorbent surface area is not the only

338 parameter that controls the sorption process however there are other parameters that may be exhibit anti-

339 synergistic effects such as the net charge of the sorbent surface. From the zeta potential analysis for the

340 applied three sorbents, it is clear that S2 and S3 have a highly negative surface (-27.9 and $-34.2 \mathrm{mV}$

341 respectively) which in turn results in the repulsion between the sorbent particles and the formation of

342 unstable complexes with the organic compounds species. However, S1 has a much lower surface charge

$343(-5.6 \mathrm{mV})$ which means that it could produce more stable complexes with organic compounds.

344 The mathematical treatment of the obtained results using Elovich equation has been performed to figure

345 out where the organic compounds adsorption process is chemical adsorption in nature or not. The plot

346 of ln t versus qt, Fig. 10, explore straight lines with a good correlation coefficient (about 0.95) for S1,

347 S2, and S3 waste sludge sorbent. This confirms that the organic compounds adsorption from crude

348 phosphoric acid using S1, S2, and S3 is a chemisorption process and the adsorption rate is exponentially

349 dependent on the number of available adsorption sites in the applied sorbents (Ali et al. 2019). Table

3504 declares that the initial adsorption rate for S1, S2, and S3 sorbents are 31.6, 14.9, and $32.8 \mathrm{mg} / \mathrm{g} . \mathrm{min}$ 
respectively. It is worth noted that, the initial sorption rate value $(\alpha)$ obtained from Elvoich model has

352 the same trend as the initial sorption rate $(\mathrm{h})$ obtained from McKay equation whereas $\mathrm{S} 1 \approx \mathrm{S} 3>\mathrm{S} 2$.

353 Nevertheless, $\alpha$ values are 4-5 times greater than $\mathrm{h}$ values.

354 Despite Pseudo-second order and Elovich kinetic models have been successfully described the nature of the organic compounds sorption process as a chemisorption reaction however, they could not give clear information regards to the organic compounds adsorption mechanism. In the solid-liquid reactions, the sorption kinetics could be controlled with numerous diffusion mechanisms; resistance to bulk diffusion, film diffusion, and intraparticle diffusion. Mainly, the resistance to film diffusion is active at the beginning of the sludge sorbents and liquid phosphoric acid. Also, by applying sufficient velocity for mixing the sludge sorbents and phosphoric acid, the effect of the resistance to bulk diffusion could be overlooked. Thus, the resistance to intraparticle diffusion is the main controlling step. Accordingly, the obtained experimental results have been analyzed using the Morris-Weber model as shown in Fig. 11. The model constants were evaluated from the plot of qt as a function of $\mathrm{t} 0.5$ and presented in Table 4 .

Fig. 11 displays two regions (multi-linear relationship) for S1, S2, and S3 sorbents which means that the intraparticle diffusion is not the only mechanism that controls the organic compounds sorption proces. This may be due to the rate of transfer of the organic compounds molecules is not the same in both sorption stages; initial and final which clears the effect of the boundary layer (Wu et al. 2009). Table 4 evident that the first stage of the organic compounds adsorption process is characterized by low boundary layer effect and in turn high sorption rate for the applied three sorbents which confirm the fast reaction. The reason beyond that may be the presence of avialable surface active sites which result in the external surface adsorption (Wu et al. 2009; Taha et al. 2019). On the contrary, the second stage is characterized by a low absorption rate and high boundary layer effect for S1, S2, and S3 sludge which could be attributed to the saturation of most sludge surface sites, accordingly the intraparticle diffusion (IPD) begins. In this regard, it could be indicated that the sorption of organic species from commercial 
375 phosphoric acid using S1, S2, and S3 sewage sludge is controlled by the combination of external surface

376 adsorption and intraparticle diffusion as rate-controlling steps (Ait Ahsaine et al. 2017; Taha et al. 2019).

377 The adsorption capacity of S1, S2 and S3 sludge sorbents has been compared with other adsorbents that

378 applied for the same purpose, removal of organic compounds recovery from crude phosphoric acid, and

379 exhibited in Table 5. The revealed data declare that the utilized three sorbents; S1, S2 and S3 possess

380 organic compounds sorption capacity within the given sorbents from literature which obvious that these

381 swage sludges could be applied for the clarification of crude phosphoric acid.

\section{$382 \quad 3.5 . \quad$ The sorption isotherm}

383 The sorption isotherm is an essential factor for the plant design and improving the adsorption system.

384 Accordingly, Freundlich and Langmuir isotherm models were applied for analyzing the obtained

385 equilibrium resluts. The coefficient of correlation $\left(\mathrm{R}^{2}\right)$ has been applied for testing the fitting of the

386 obtained data to the isotherm equations. The linear form of Freundlich and Langmuir isotherm models

387 have commonly expressed equations 1 and 2, respectively (Hussein and Taha 2013):

$$
\begin{aligned}
\log q_{e} & =\log K_{F}+\frac{1}{n} \log C_{e} \ldots \ldots(7) \\
\frac{C_{e}}{q_{e}} & =\frac{1}{k_{L} q_{m}}+\frac{C_{e}}{q_{m}} \ldots \ldots(8)
\end{aligned}
$$

where $\mathrm{K}_{\mathrm{f}}(\mathrm{L} / \mathrm{mg})$ is corresponding to the sorption capacity, and $\mathrm{n}$ refers to the sorption intensity. $\mathrm{q}_{\mathrm{m}}(\mathrm{mg}$.

$\left.\mathrm{g}^{-1}\right)$ is the maximum sorption capacity of the sorbent, and $\mathrm{k}_{\mathrm{L}}\left(\mathrm{L} \cdot \mathrm{mg}^{-1}\right)$ is the equilibrium constant which, refers to the energy of adsorption and reflects the affinity of resin towards the organic compounds.

The isotherm parameters of Freundlich model have been evaluated from the illustration of ln qe as a

394 function of In Ce, Fig. 12, and presented in Table 6. Nevertheless, the parameters of Langmuir model

395 were obtained from the Figure of Ce/qe as a function of $\mathrm{Ce}$ and displayed in Table 6.

396 The explored results in Figs. 12 and 13 as well as Table 6, declare that only Freundlich isotherm plot 397 gives a straight line with a perfect correlation coefficient (about 0.98) for all investigated sorbents. This 
398 indicates that the organic compounds adsorption from crude dihydrate phosphoric acid using S1, S2, and

399 S3 waste sludge is fitting Freundlich isotherm model which means a heterogeneous sorption system with

400 different active sites. Furthermore, Table 6 shows that $n>1$ for the applied three waste sludge sorbents

401 which obvious that the sorption is a physical process (Dacrory et al. 2020; Masoud 2020).

402 4. Conclusions

403 Bis [tert-butyl(dimethyl)silyl] azelaate, 2,6-Di-tert-butyl-4-methylphenol, and Dibutyl phthalate 404 compounds have been detected as the main organic compounds in crude phosphoric acid. Waste sludge 405 namely, S1, S2 and S3, has been successfully utilized for the clarification of crude phosphoric acid. The 406 main variables that affect the organic compounds sorption efficiency such as: shaking time, sorbent dose, 407 and phosphoric acid concentration were studied. The revealed data declare that the adsorption reaction 408 is fast whereas the reaction equilibrium has been reached after $30 \mathrm{~min}$ for the three investigated sorbents. 409 The sorbent does have positive impact on the sorption percent on the other hand the phosphoric acid 410 concentration has negative influence. The sorption kinetics has been performed using pseudo-first-order, 411 pseudo-second order, Elvoich, and Weber-Morris kinetic models. The displayed results explore that the 412 S1, S2 and S3 sorbent exhibit chemisorption reaction. S1 waste sludge exhibit the highest sorption 413 capacity, while S3 shows the lowest sorption capacity. 


\section{Declarations}

\section{$423 \quad$ 5.1. Ethics approval and consent to participate}

424 Not applicable

\section{$425 \quad$ 5.2. Consent for publication}

426 Not applicable

\section{5.3. Availability of data and materials}

428 All data generated or analysed during this study are included in this published article.

429 5.4. Competing interests

430 The authors declare that they have no competing interests.

\section{$431 \quad$ 5.5. Funding}

432 The authors did not receive support from any organization for the submitted work.

433 The authors have no relevant financial or non-financial interests to disclose.

\section{$434 \quad$ 5.6. Authors' contributions}

435 All authors have equal contributions in the established of the research ides, experimental part, 436 characterization, and explanation of results and shared in writing and revise the manuscript. 


\section{References}

447 Abdelraof M, Ibrahim S, Selim MH, Hasanin M (2020) Immobilization of L-methionine $\gamma$-lyase on

448 different cellulosic materials and its potential application in green-selective synthesis of volatile 449 sulfur compounds. J Environ Chem Eng 8:. https://doi.org/10.1016/j.jece.2020.103870

450 Abo-El-Enein SA, Shebl A, Abo El-Dahab SA (2017) Drinking water treatment sludge as an efficient 451

Ahmed HM, Abdellatif MM, Ibrahim S, Abdellatif FHH (2019) Mini-emulsified Copolymer/Silica nanocomposite as effective binder and self-cleaning for textiles coating. Prog Org Coatings 129:5258. https://doi.org/10.1016/j.porgcoat.2019.01.002

Ait Ahsaine H, Zbair M, El Haouti R (2017) Mesoporous treated sewage sludge as outstanding low-cost adsorbent for cadmium removal. Desalin Water Treat 85:330-338. https://doi.org/10.5004/dwt.2017.21310

Ali MM, Attia AA, Taha MH, et al (2019) Application of acid activated bentonite for efficient removal of organic pollutants from industrial phosphoric acid: Kinetic and thermodynamic study. In: SPE Middle East Oil and Gas Show and Conference, MEOS, Proceedings

Awwad NS, El-Nadi YA, Hamed MM (2013) Successive processes for purification and extraction of phosphoric acid produced by wet process. Chem Eng Process - Process Intensif 74:69-74. https://doi.org/10.1016/j.cep.2012.11.009

Bogusz A, Oleszczuk P, Dobrowolski R (2019) Adsorption and desorption of heavy metals by the sewage sludge and biochar-amended soil. Environ Geochem Health 41:1663-1674. https://doi.org/10.1007/s10653-017-0036-1

Bui TT, Giovanoulis G, Cousins AP, et al (2016) Human exposure, hazard and risk of alternative plasticizers to phthalate esters. Sci. Total Environ. 541:451-467 
470 Cordell D, Turner A, Chong J (2015) The hidden cost of phosphate fertilizers: mapping multi471 stakeholder supply chain risks and impacts from mine to fork. Glob Chang Peace Secur 27:323-343. $472 \quad$ https://doi.org/10.1080/14781158.2015.1083540

473 Cordell D, White S (2014) Life's bottleneck: Sustaining the world's phosphorus for a food secure future. $474 \quad$ Annu. Rev. Environ. Resour. 39:161-188

475 Dacrory S, Haggag ESA, Masoud AM, et al (2020) Innovative synthesis of modified cellulose derivative 476 as a uranium adsorbent from carbonate solutions of radioactive deposits. Cellulose 27:7093-7108. 477 https://doi.org/10.1007/s10570-020-03272-w

478 Degen T, Sadki M, Bron E, et al (2014) The high score suite. In: Powder Diffraction. pp S13-S18

479 Dissanayake CB, Chandrajith R (2009) Phosphate Mineral Fertilizers, trace metals and human health. J. $480 \quad$ Natl. Sci. Found. Sri Lanka 37:153-165

481 El Naggar AMA, Ali MM, Abdel Maksoud SA, et al (2019) Waste generated bio-char supported co482 nanoparticles of nickel and cobalt oxides for efficient adsorption of uranium and organic pollutants 483 from industrial phosphoric acid. J Radioanal Nucl Chem 320:741-755. 484 https://doi.org/10.1007/s10967-019-06529-2

485 Evuti AM, Lawal M Recovery of coagulants from water works sludge: A review. researchgate.net 486 FAO (2018) Feeding nine billion in 2050. In: Rome. 487 http://www.fao.org/news/story/en/item/174172/icode/. Accessed 17 Nov 2020

488 Fawzy MM, Farag NM, Amin AS (2018) Treatment of Crude Phosphoric Acid from Some Undesirable 489 Impurities. J Basic Environ Sci 5:204-216

490 Fayiga AO, Nwoke OC (2016) Phosphate rock: Origin, importance, environmental impacts, and future $491 \quad$ roles. Environ. Rev. 24:403-415

492 Grassi M, Kaykioglu G, Belgiorno V, Lofrano G (2012) Removal of Emerging Contaminants from 493 Water and Wastewater by Adsorption Process. pp 15-37 
494 Hamza W, Chtara C, Benzina M (2013) Retention of organic matter contained in industrial phosphoric 495 acid solution by raw Tunisian clays: Kinetic equilibrium study. J Chem 2013:. 496 https://doi.org/10.1155/2013/218786

497 Hamza W, Chtara C, Benzina M (2015) Characterization and application of Fe and iso-Ti-pillared 498 bentonite on retention of organic matter contained in wet industrial phosphoric acid (54\%): kinetic 499 study. Res Chem Intermed 41:6117-6140. https://doi.org/10.1007/s11164-014-1726-2

500 He L, Gielen G, Bolan NS, et al (2015) Contamination and remediation of phthalic acid esters in $501 \quad$ agricultural soils in China: a review. Agron. Sustain. Dev. 35:519-534

502 Hellal F, El-Sayed S, Zewainy R, Amer A (2019) Importance of phosphate pock application for 503 sustaining agricultural production in Egypt. Bull Natl Res Cent 43:. https://doi.org/10.1186/s42269$504 \quad 019-0050-9$

505 Hussein AEM, Taha MH (2013) Uranium removal from nitric acid raffinate solution by solvent 506 immobilized PVC cement. J Radioanal Nucl Chem 295:709-715. https://doi.org/10.1007/s10967$507 \quad 012-2158-3$

508 Ibrahim S, Abdel Rehim M, Turky G (2018) Dielectric study of polystyrene/polycaprolactone 509 composites prepared by miniemulsion polymerization. J Phys Chem Solids 119:56-61. $510 \quad$ https://doi.org/10.1016/j.jpcs.2018.03.030

511 Ibrahim S, Abdelfattah I, Soliman O (2016) Environmental recycling of compact disc using industrial $512 \quad$ wastewater. Der Pharm Lett 8:207-214

513 Ibrahim S, Voit B (2009) Synthesis and characterization of well-defined block copolymers by combing 514 controlled radical and cationic polymerization. In: Macromolecular Symposia. pp 59-66

515 Jamshidi M, Jamshidi A, Mehrdadi N (2012) APPLICATION OF SEWAGE DRY SLUDGE IN 516 CONCRETE MIXTURES

517 Kang HJ, Kim JH (2019) Adsorption Kinetics, Mechanism, Isotherm, and Thermodynamic Analysis of 

24:513-521. https://doi.org/10.1007/s12257-019-0001-1

520 Kim YS, Kim JH (2019) Isotherm, kinetic and thermodynamic studies on the adsorption of paclitaxel 521 onto Sylopute. J Chem Thermodyn 130:104-113. https://doi.org/10.1016/j.jct.2018.10.005

522 Lützow M V., Kögel-Knabner I, Ekschmitt K, et al (2006) Stabilization of organic matter in temperate 523 soils: Mechanisms and their relevance under different soil conditions - A review. Eur. J. Soil Sci. $524 \quad 57: 426-445$

525 Masoud AM (2020) Sorption behavior of uranium from Sulfate media using purolite A400 as a strong 526 base anion Exchange resin. Int $\mathrm{J}$ Environ Anal Chem. $527 \quad$ https://doi.org/10.1080/03067319.2020.1763974

528 Meawad A, Ibrahim S (2019) Novel bifunctional dispersing agents from waste PET packaging materials 529 and interaction with cement. Waste Manag $530 \quad$ https://doi.org/10.1016/j.wasman.2019.01.028

531 Morsy AMA, Hussein AEM (2012) Retention of Uranium from Liquid Waste Soiution onto. Arab Conf $532 \quad$ Peac use At Energy

533 Nawar N, Ahmad ME, Said WM El, et al (2015) Adsorptive Removal of Phosphorous from Wastewater 534 Using Drinking Water TreatmentAlum Sludge (DWTAS) as Low Cost Adsorbent Citation. Am J $535 \quad$ Chem Appl 2:7985

536 Nedelciu CE, Ragnarsdóttir KV, Stjernquist I, Schellens MK (2020) Opening access to the black box: 537 The need for reporting on the global phosphorus supply chain. Ambio 49:881-891. $538 \quad$ https://doi.org/10.1007/s13280-019-01240-8

539 Norwegian Scientific Committee for Food Safety (2009) Opinion of the Panel on Food Additives, 540 Flavourings, Processing Aids, Materials in Contact with Food and Cosmetics of the Norwegian $541 \quad$ Scientific Committee for Food Safety 
542 Ragheb S (2018) Removal of Heavy Metals from Wastewater Using Sewage Sludge Ash (SSA) as

543 Adsorbent. SSRN Electron J. https://doi.org/10.2139/ssrn.3164094

544 Rashed MN (2018) Heavy Metals Removal from Wastewater by Adsorption on Modified Physically

545 Activated Sewage Sludge. Arch Org Inorg Chem Sci 1.

$546 \quad$ https://doi.org/10.32474/aoics.2018.01.000102

547 Ryssel ST, Arvin E, Lützhøft HCH, et al (2015) Degradation of specific aromatic compounds migrating

548 from PEX pipes into drinking water. Water Res 81:269-278.

$549 \quad$ https://doi.org/10.1016/j.watres.2015.05.054

550 Setia R, Rengasamy P, Marschner P (2014) Effect of mono- and divalent cations on sorption of water-

551 extractable organic carbon and microbial activity. Biol Fertil Soils 50:727-734.

552 https://doi.org/10.1007/s00374-013-0888-1

553 Shahat AA, Ibrahim AY, Hendawy SF, et al (2011) Chemical composition, antimicrobial and antioxidant

554 activities of essential oils from organically cultivated fennel cultivars. Molecules 16:1366-1377.

$555 \quad$ https://doi.org/10.3390/molecules16021366

556 Singh DK, Mondal S, Chakravartty JK (2016) Recovery of Uranium from Phosphoric Acid: A Review.

557 Solvent Extr Ion Exch 34:201-225. https://doi.org/10.1080/07366299.2016.1169142

558 Stewart WM, Roberts TL (2012) Food security and the role of fertilizer in supporting it. In: Procedia

$559 \quad$ Engineering. pp 76-82

560 Taha MH, Abdel Maksoud SA, Ali MM, et al (2019) Conversion of biomass residual to acid-modified

561 bio-chars for efficient adsorption of organic pollutants from industrial phosphoric acid: an

562 experimental, kinetic and thermodynamic study. Int J Environ Anal Chem 99:1211-1234.

$563 \quad$ https://doi.org/10.1080/03067319.2019.1618459

564 Taha MH, El-Maadawy MM, Hussein AEM, Youssef WM (2018) Uranium sorption from commercial

565 phosphoric acid using kaolinite and metakaolinite. J Radioanal Nucl Chem 317:685-699. 
567 US National Library of Medicine (2020) Butylated hydroxytoluene | C15H24O - PubChem

568 Wheeler DL, Chappey C, Lash AE, et al (2000) Database resources of the National Center for 569 Biotechnology Information. Nucleic Acids Res. 28:10-14

570 Wołowiec M, Bajda T (2017) Current stage of knowledge relating to the use ferruginous sludge from 571 water treatment plants-a preliminary review of the literature. MINERALOGIA 48:39-45. $572 \quad$ https://doi.org/10.1515/mipo-2017-0010

573 Wołowiec M, Komorowska-Kaufman M, Pruss A, et al (2019) Removal of heavy metals and metalloids 574 from water using drinking water treatment residuals as adsorbents: A review. Minerals 9

575 Wu FC, Tseng RL, Juang RS (2009) Initial behavior of intraparticle diffusion model used in the 576 description of adsorption kinetics. Chem Eng J 153:1-8. https://doi.org/10.1016/j.cej.2009.04.042

577 Yu L, Zhong Q (2006) Preparation of adsorbents made from sewage sludges for adsorption of organic 578 materials from wastewater. Hazard Mater 137:359-366. https://doi.org/10.1016/j.jhazmat.2006.02.007

Zhang M, Zhang H (2010) Co-transport of dissolved organic matter and heavy metals in soils induced by excessive phosphorus applications. J Environ Sci 22:598-606. https://doi.org/10.1016/S10010742(09)60151-0

Zhang R, Chen C, Li J, Wang X (2015) Preparation of montmorillonite@carbon composite and its and Calcined Layered Double Oxides for the Efficient Removal of U(VI) from Wastewater Solutions. ACS Sustain Chem Eng 5:1173-1185. https://doi.org/10.1021/acssuschemeng.6b02550 
Dibutyl phthalate.

In:

Natl.

Cent.

Biotechnol.

Inf.

591 https://pubchem.ncbi.nlm.nih.gov/compound/Potassium-ion. 
Figures
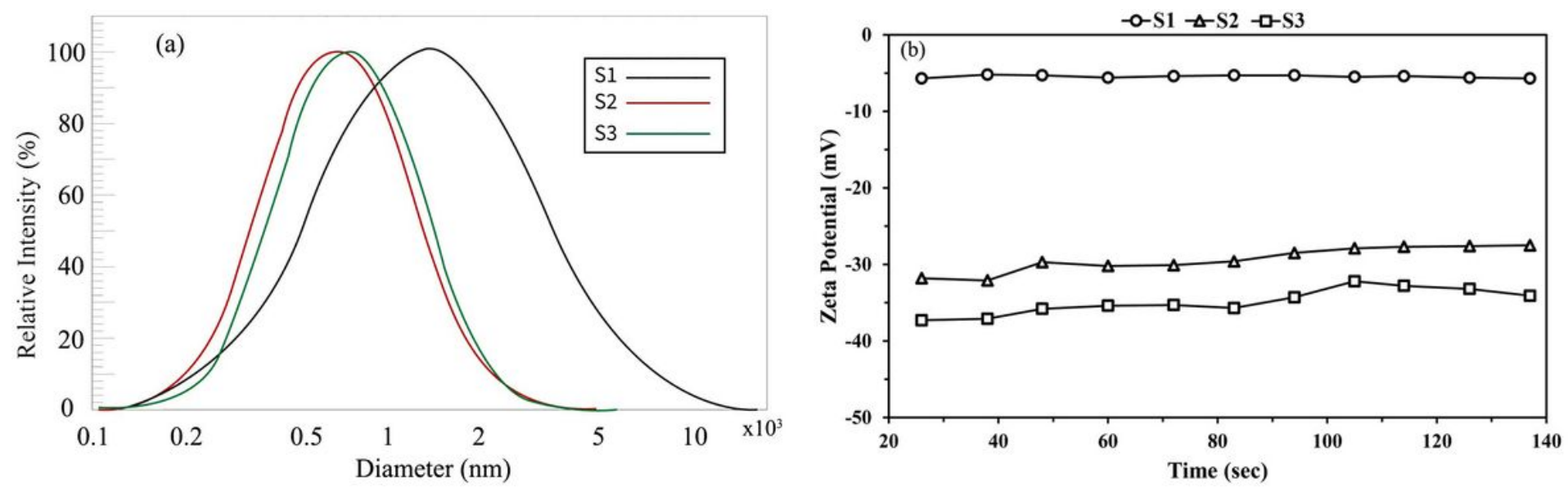

Figure 1

a: Particle size distribution of WTS samples. b: Zeta potential of different WTS samples.

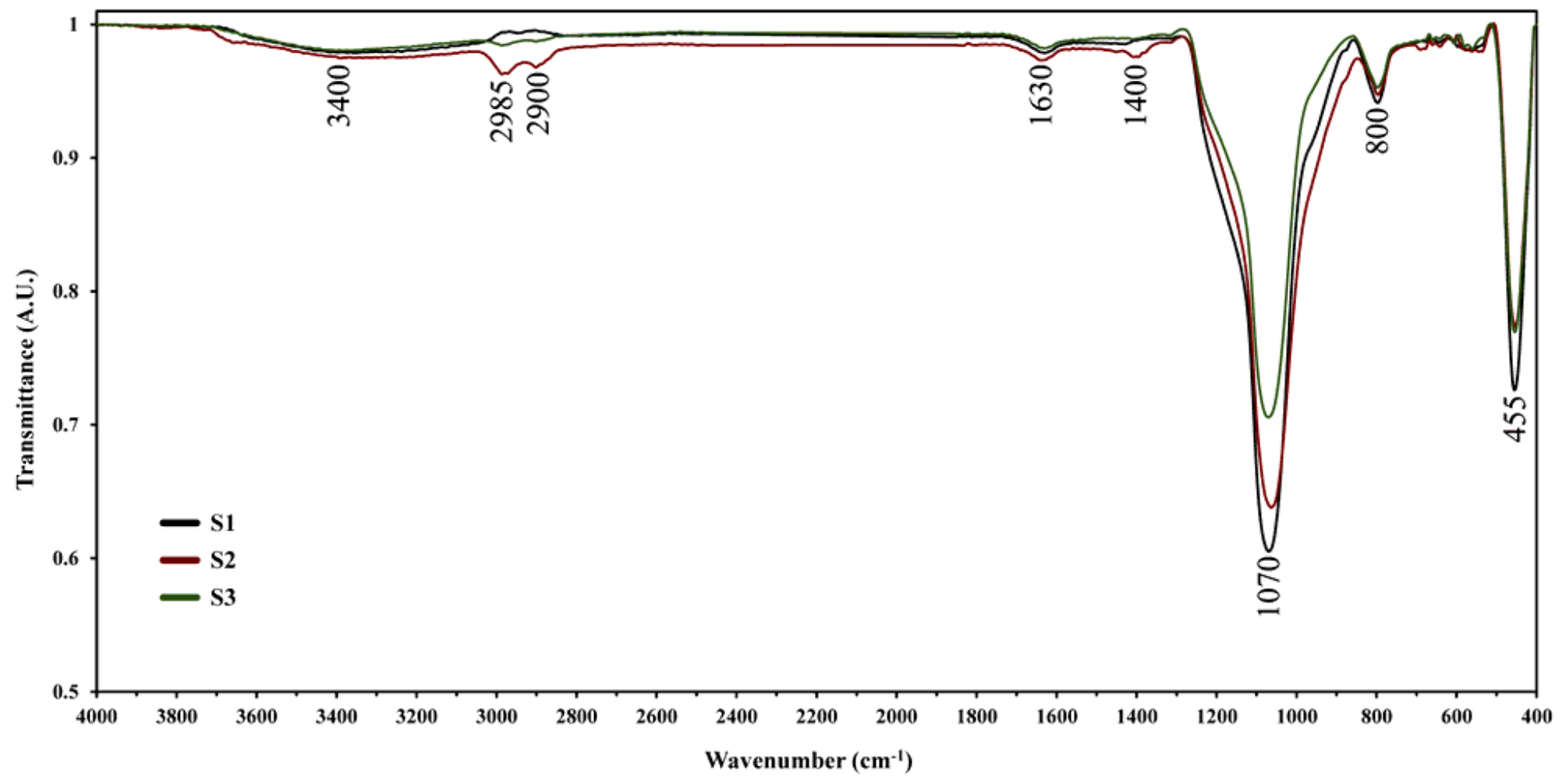

Figure 2

FTIR spectra of WTS samples. 


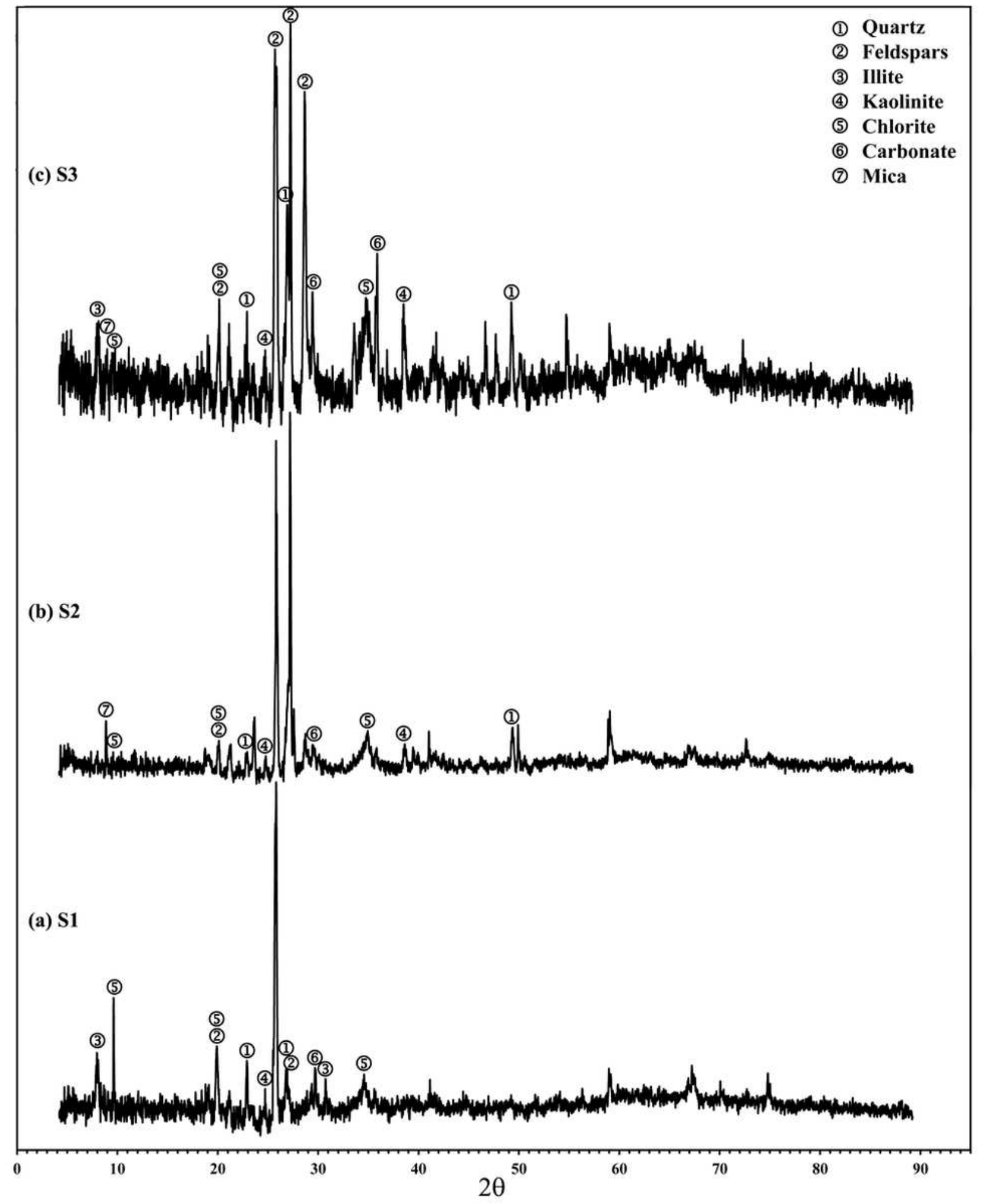

Figure 3

X-ray diffraction patterns of WTS samples. 

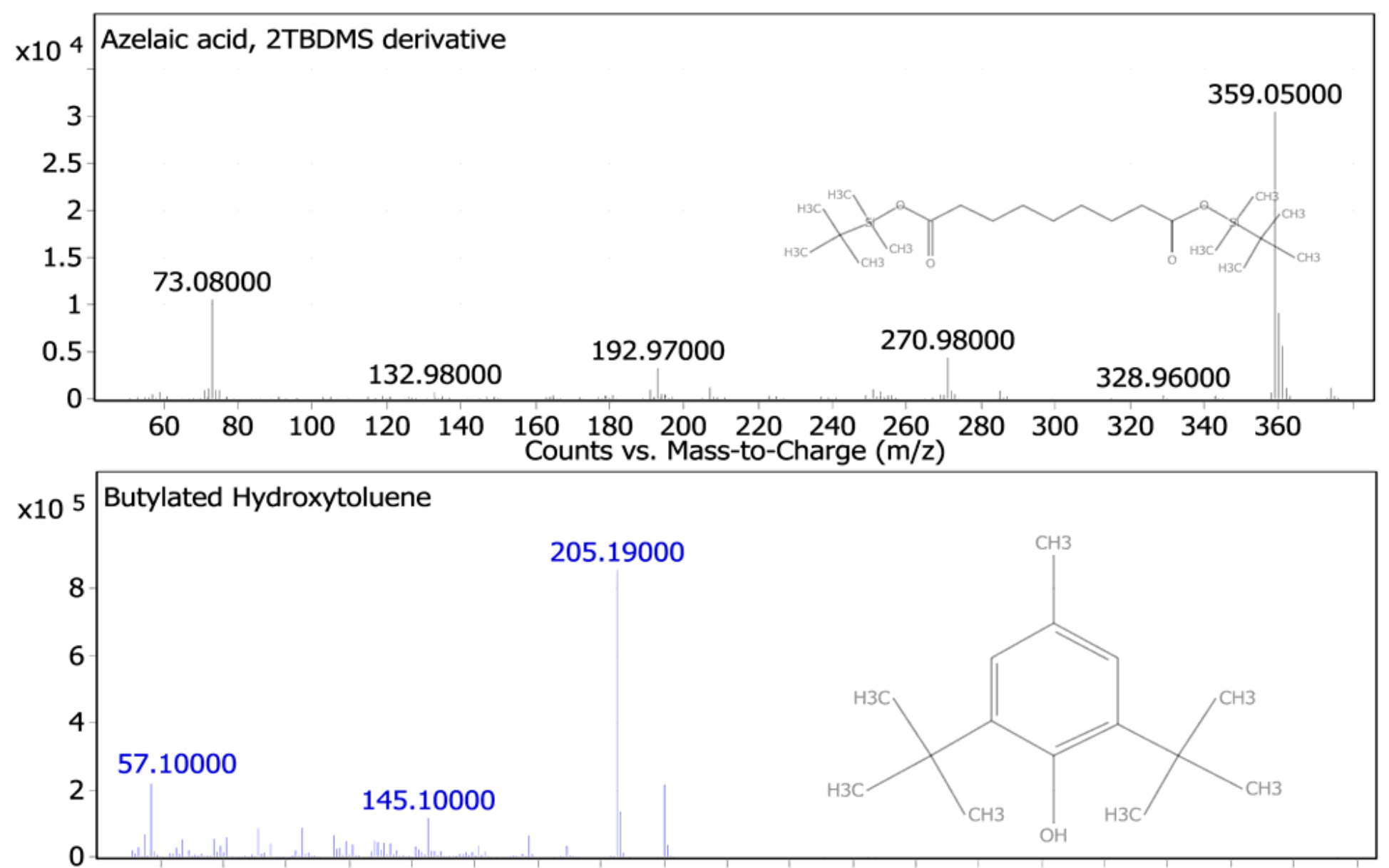

$60 \quad 80 \quad 100120140160180200220240 \quad 260 \quad 280300320340360380400420$ Counts vs. Mass-to-Charge ( $\mathrm{m} / \mathrm{z})$

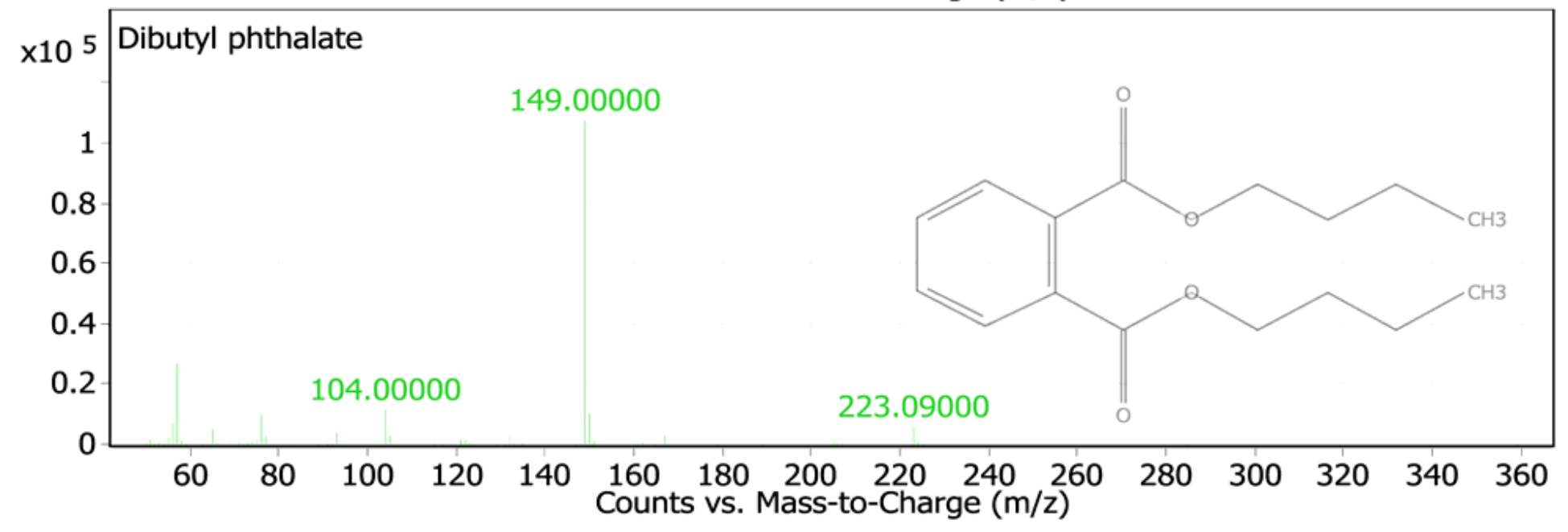

Figure 4

The main organic components in the crude phosphoric acid 


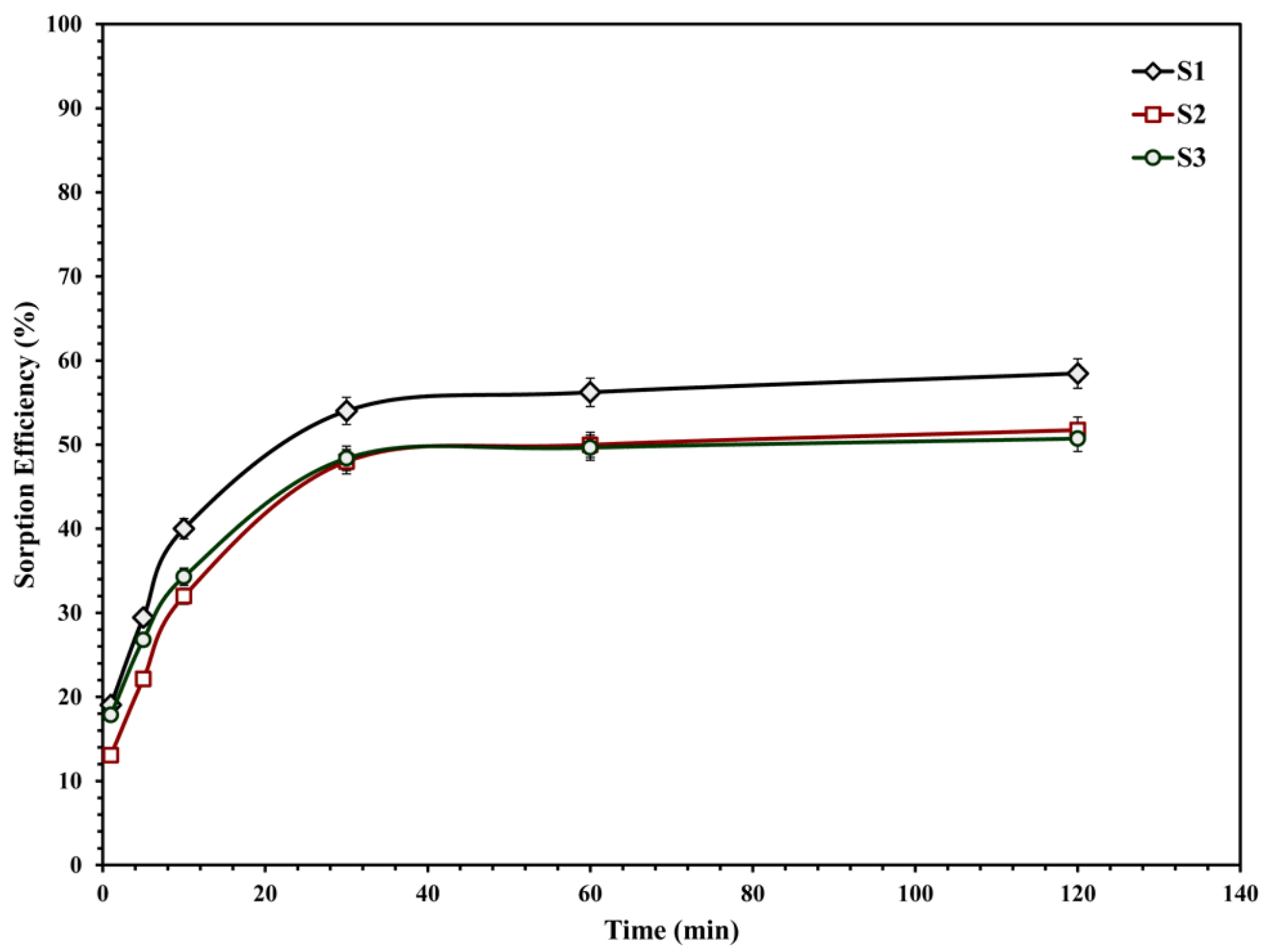

Figure 5

Organic matter sorption efficiency as a function of shaking time. 


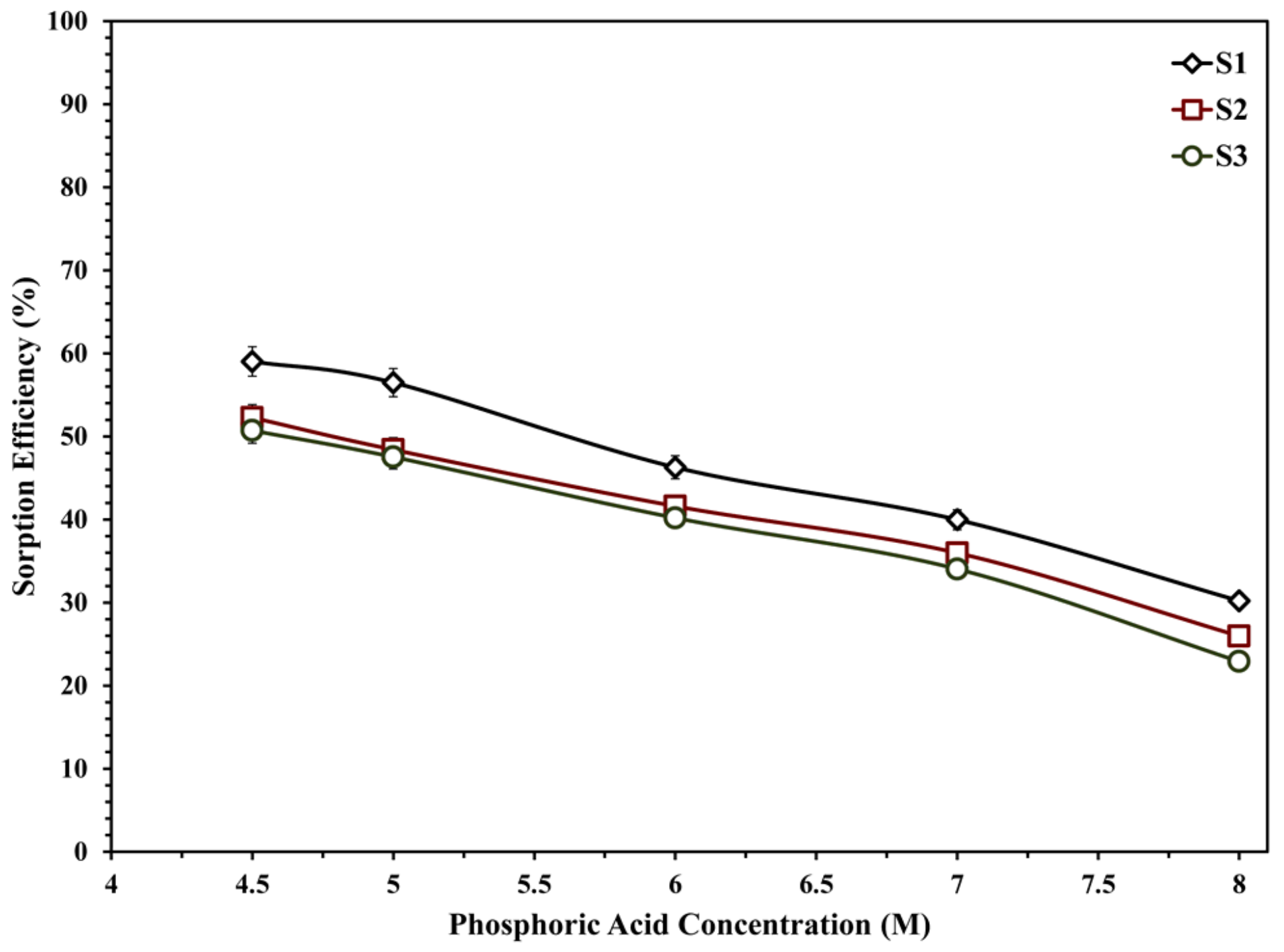

Figure 6

Organic matter sorption efficiency as a function of phosphoric acid concentration. 


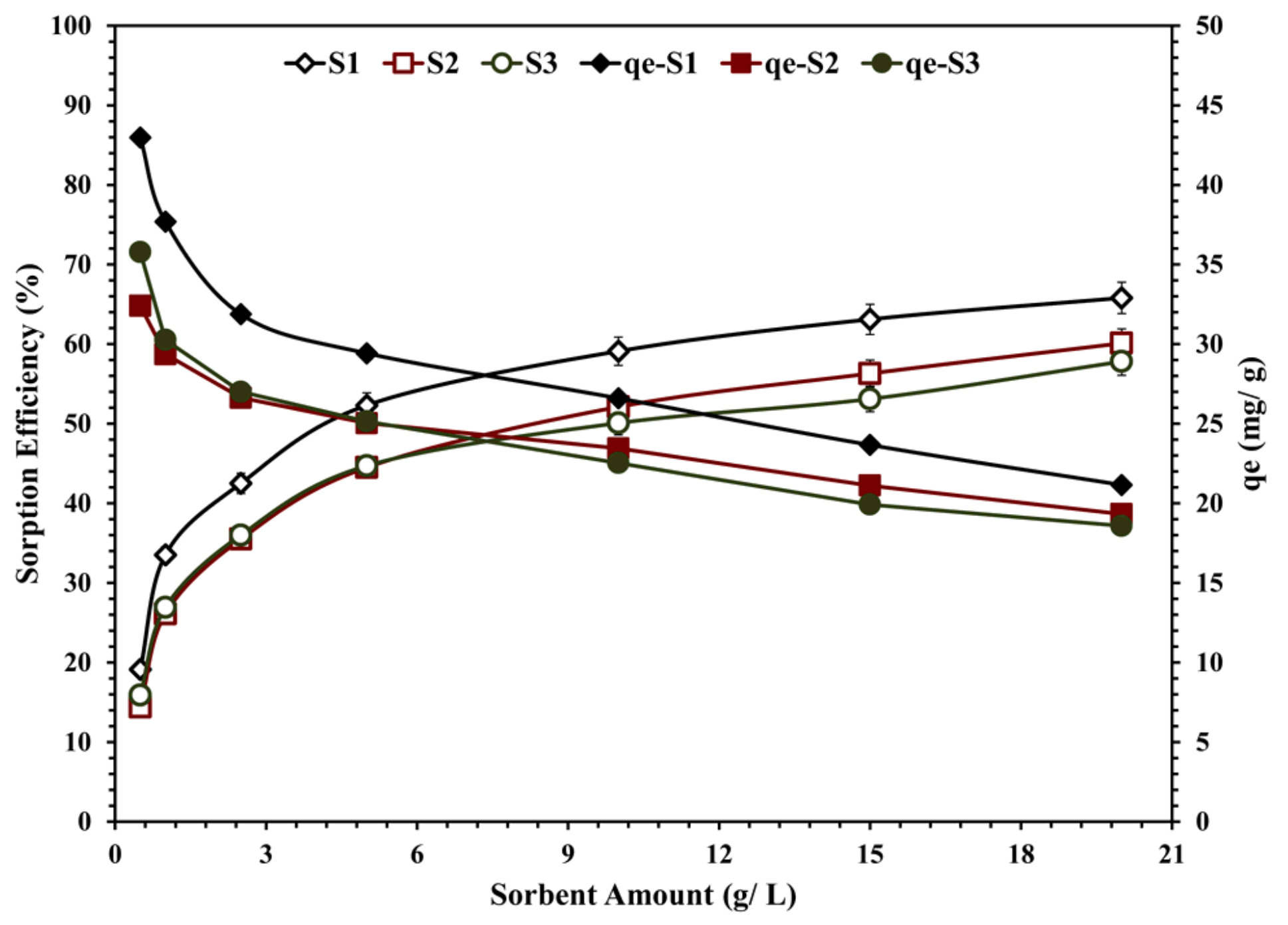

Figure 7

Organic matter sorption efficiency as a function of sorbent amount of addition. 


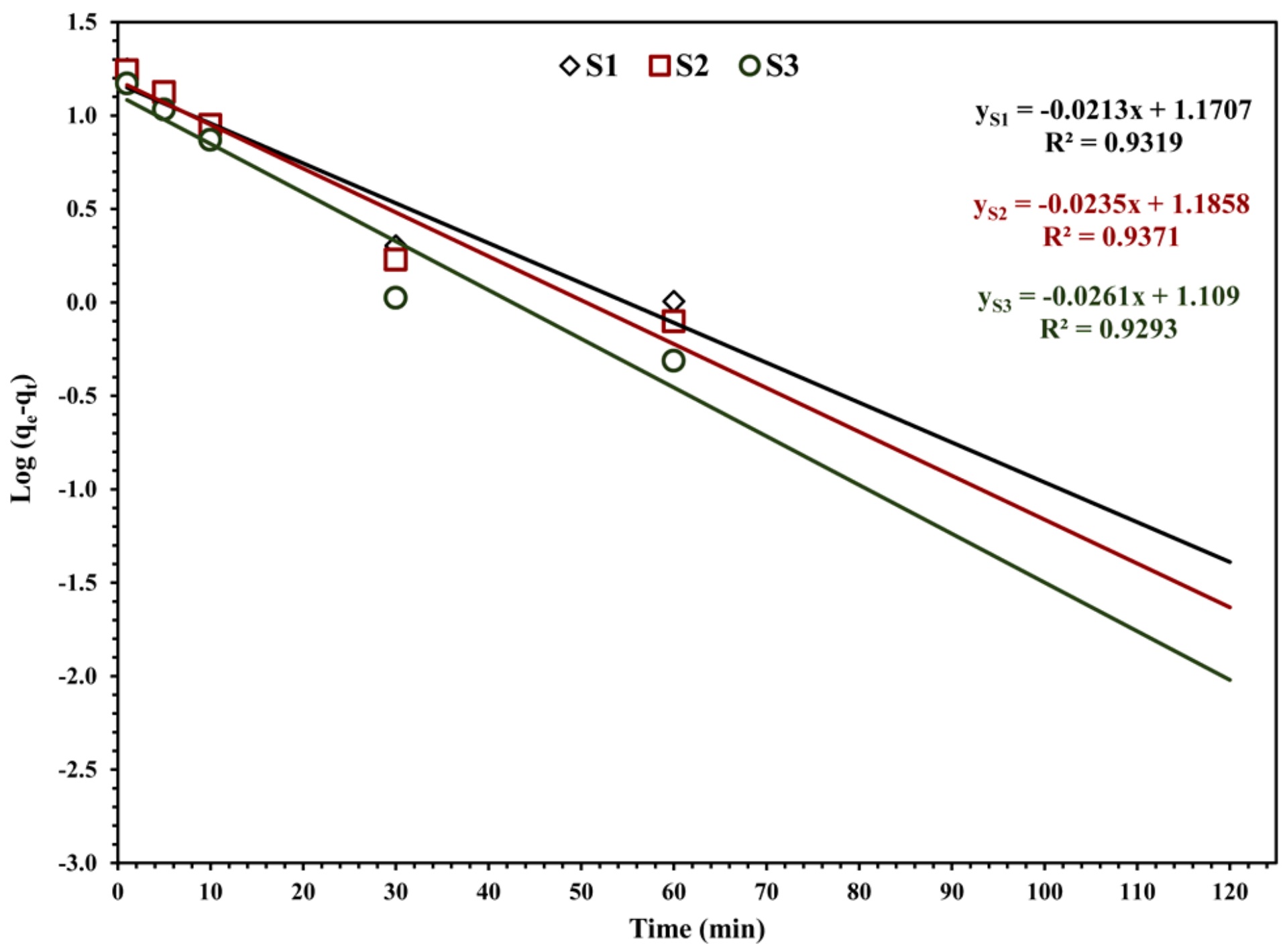

Figure 8

Lagergreen plot for organic matter sorption using WTS. 


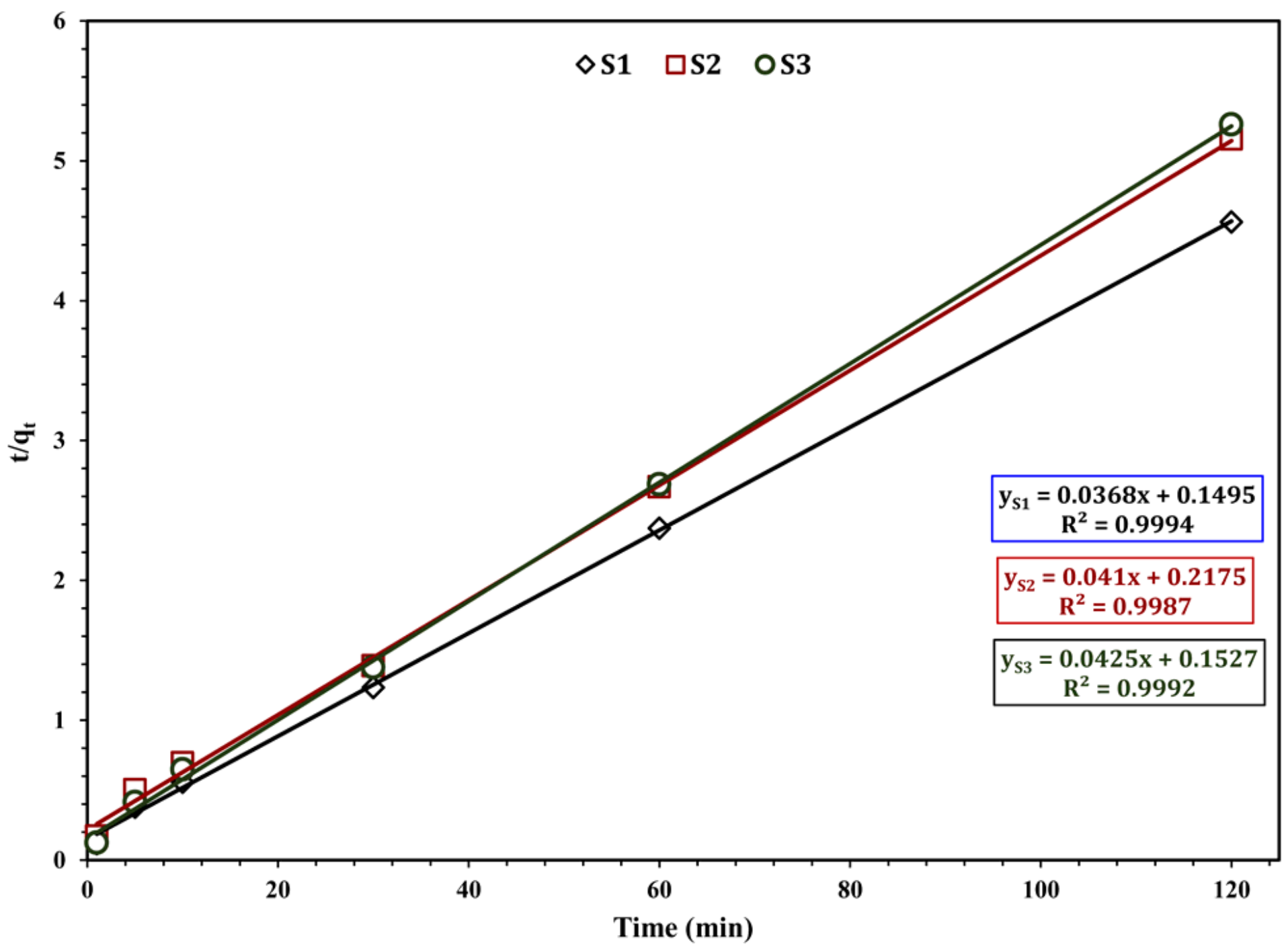

Figure 9

Pseudo second-order plot for organic matter sorption using WTS. 


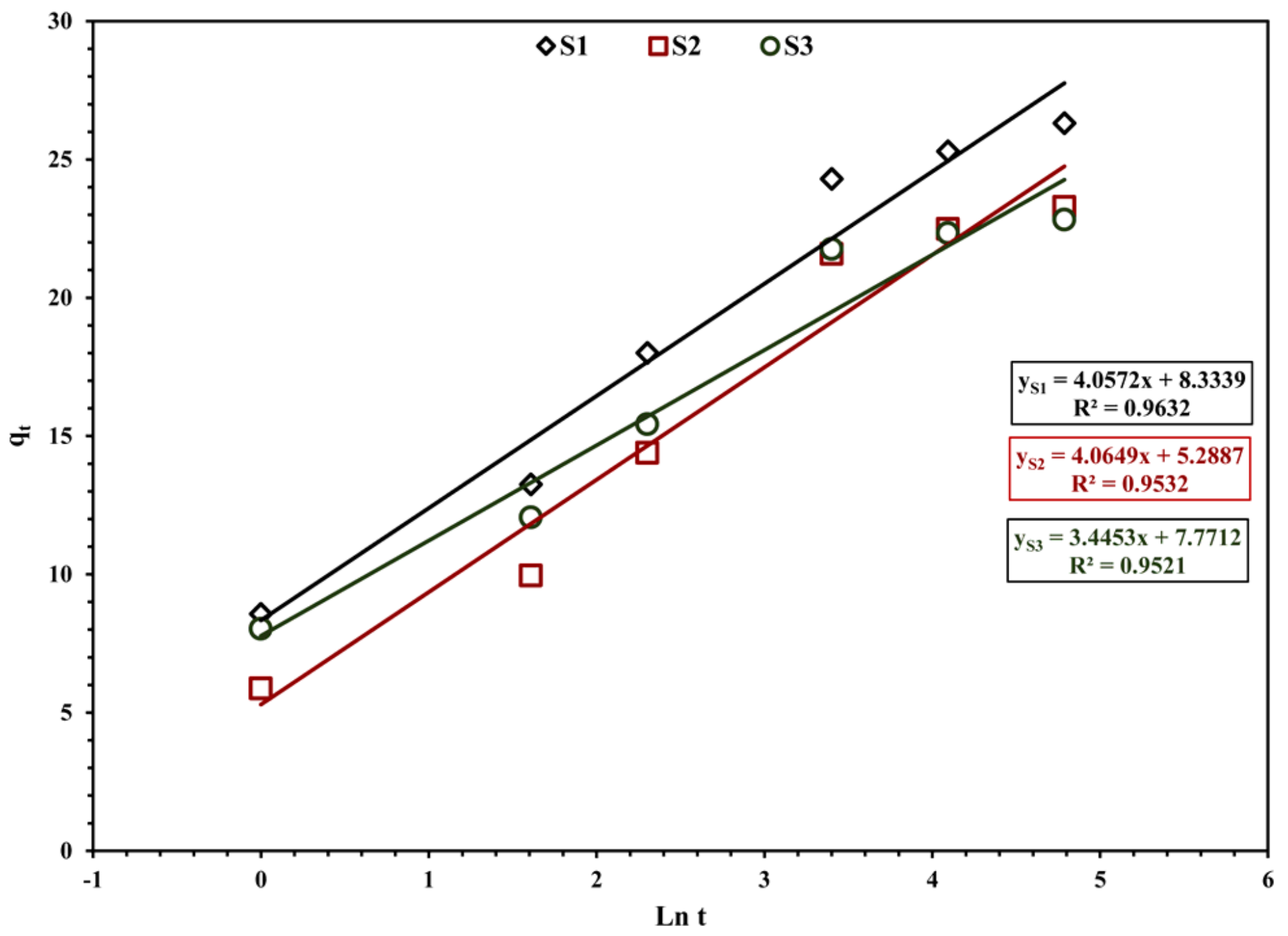

Figure 10

Elovich model plot for organic matter sorption using WTS. 


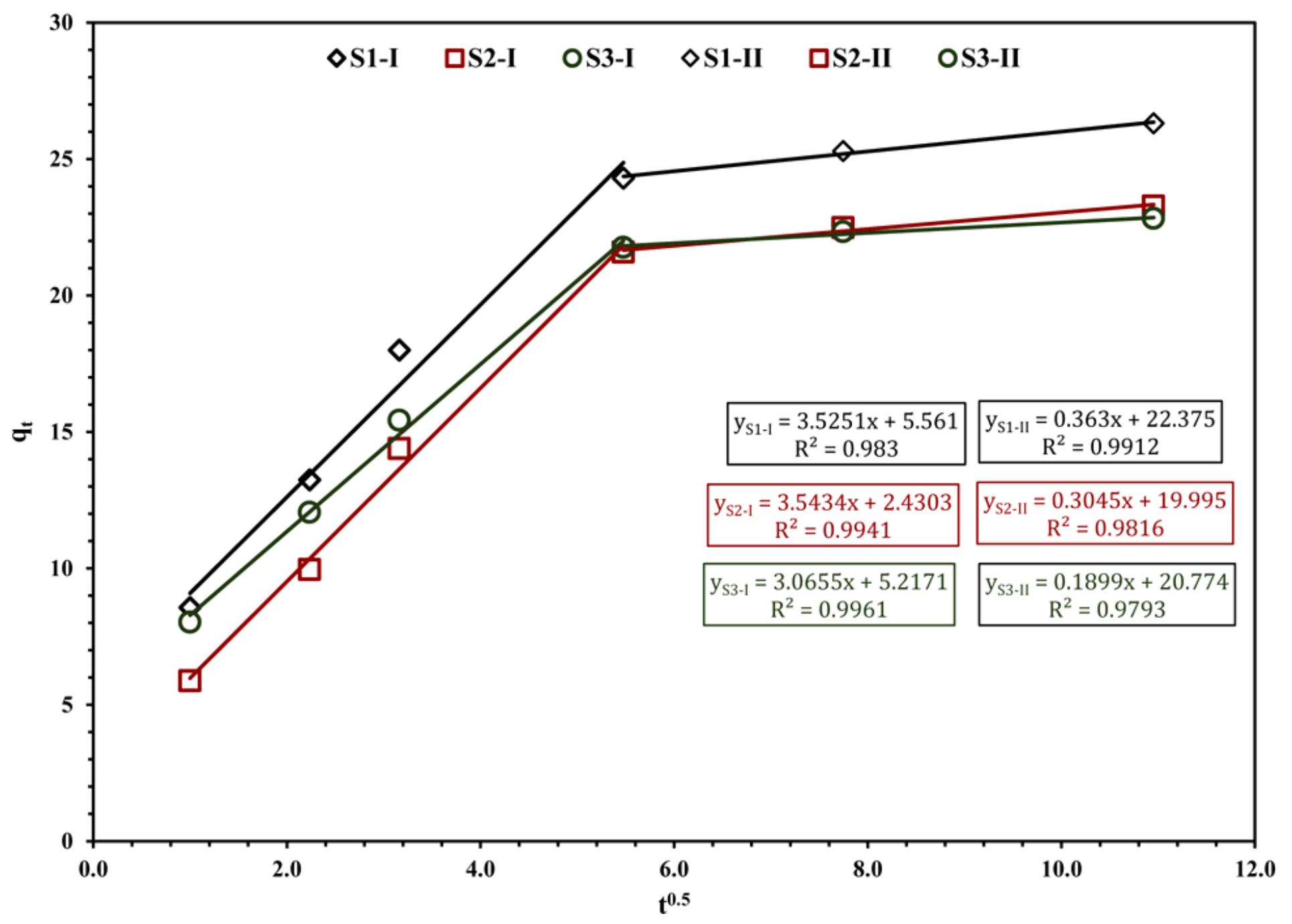

Figure 11

Weber and Morris illustration for organic matter sorption using WTS. 


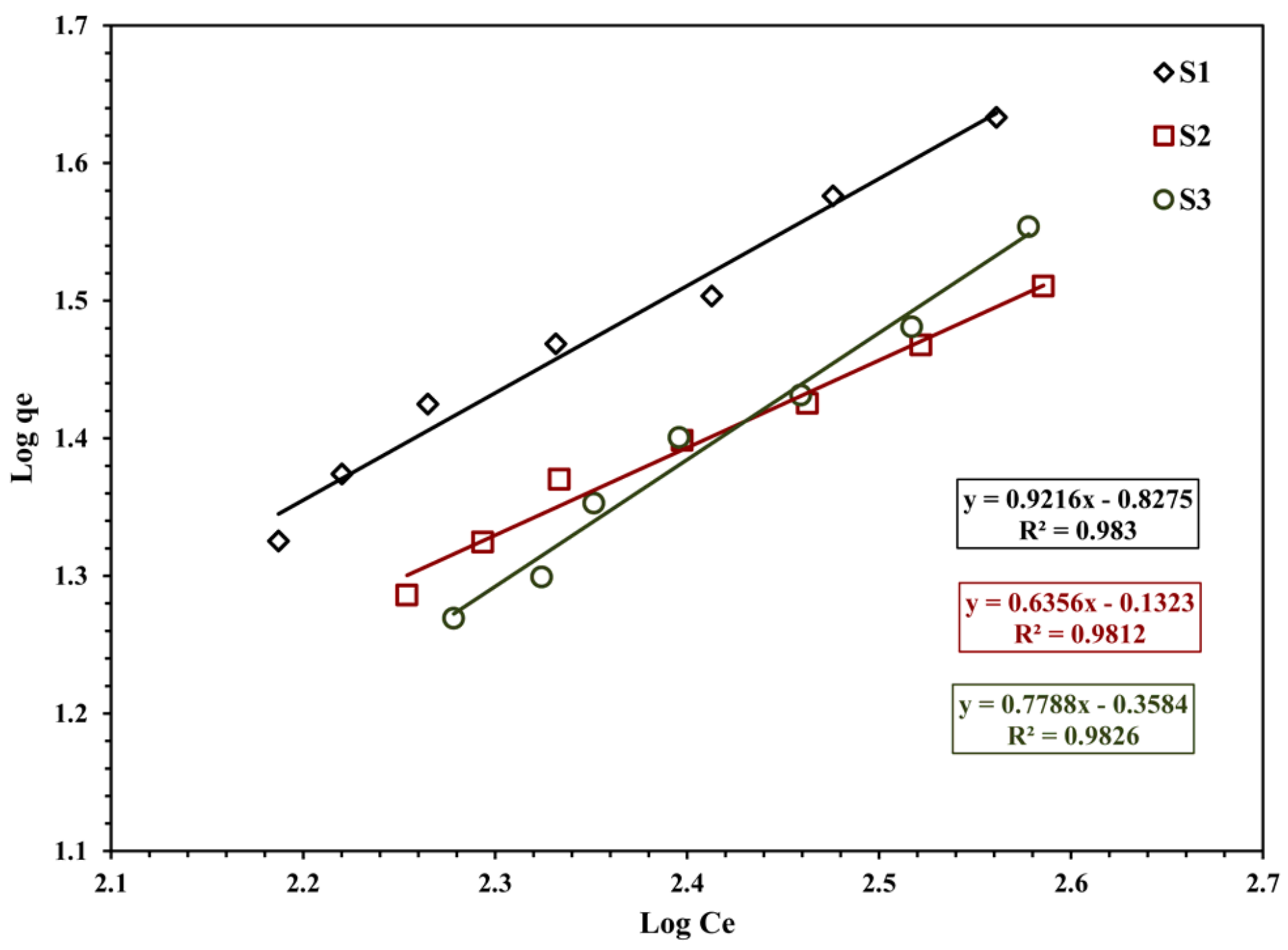

Figure 12

Freundlich model plot for organic matter sorption using different WTS samples. 


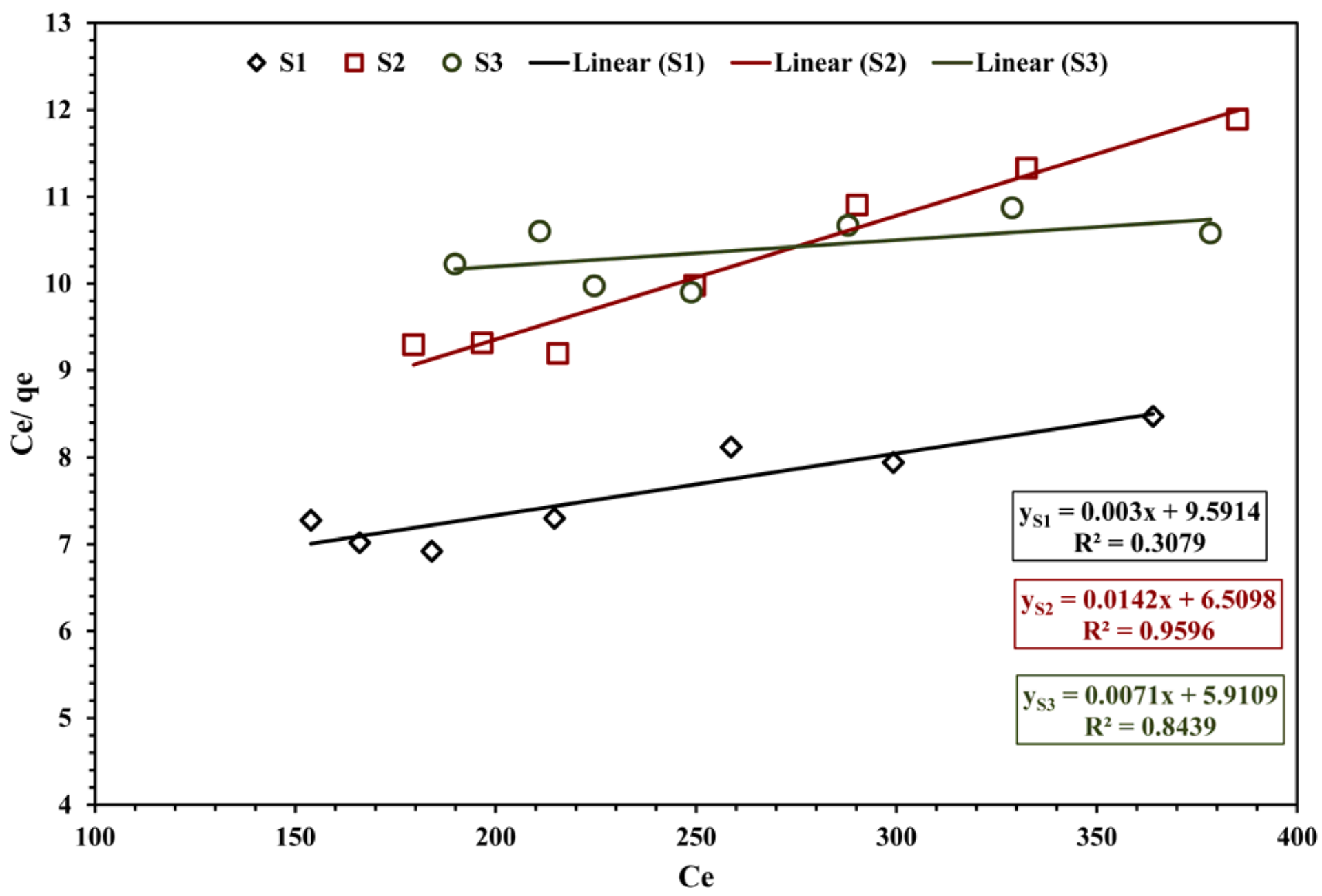

Figure 13

Langmuir model plot for organic matter sorption using different WTS samples. 